\title{
THE TERM “SCHIST."
}

Sir,-Undoubtedly Mr. Rutley is right in his etymology of the word "schist," and can produce authorities for the sense in which he proposes to use it; but notwithstanding this, and Mr. Allport's support, I must confess inyself a schismatic.

But as authority has been named, I will also quote one by way of adding to the confusion, "It would be well to describe no structure as slaty or fissile except cases of transverse cleavage" (Sedgwick, Structure of Large Mineral Masses, Tr. G. S. ser. 2, vol. iii. p. 480). Mr. Rutley says (p. 239), "I use schistose and fissile as convertible terms when the fission is not of that perfect kind which characterizes slates and shales." I confess, indeed, that I can see no reason etymological or otherwise why, if the term "schist" is to be extended beyond metamorphic rocks, those with slaty eleavage should be excluded.

"The correct application" of these terms must, no doubt, to some extent "depend on usage," but then we must be satisfied that usage has not proceeded from inaccuracy and will not give rise to inconvenience. Surely it is always lawful to fix the sense of a term which previously has been rather vague. This Prof. Jukes attempted to do, as I venture to think, wisely, well, and intelligibly. Schists, then, in his sense (and I believe it one very commonly in use among geologists) are metamorphic rocks with a fissile structure due to the arrangement of their mineral constituents. Schistose rocks are those which possess this property or seem to possess it; while slates have the property of cleavage; shales of lamination. Thus all schists are in some sense foliated rocks, though it is possible a foliated rock (as sometimes happens with gneiss) may not be strictly a schist. With such a limitation of the term we know what a writer means. Just think of the confusion which is caused when, on meeting with the word schist, we are uncertain whether the author is speaking of a rock that has undergone great chemical alteration or practically none at all. Seeing then that (as it seems to me) Prof. Jukes's limitation supplies us with a term which we really want, I trust that no attempt will be made to extend the name "schist" beyond the group of metamorphic rocks.

T. G. BonneY.

\section{ECCENTRICITY AND GLACIAL EPOCHS.}

SrR,-There are some points in Mr. Hill's remarks as to the causes of a Glacial Epoch which I think require rectifying. He admits that the total amount of heat radiated by the sun and received by any portion of the earth in any one year is a fixed amount. In his letter in your issue of April, he admits as probable, that the heat given up in the formation of snow, being disengaged in the upper regions produces little effect at the ground. Now, granting these, I think it is clearly demonstrable that a Glacial Epoch may be caused by an increased snowfall. For say in any region we have through increased eccentricity a fall of two feet of snow as against a fall of one foot before such increase of eccentricity. Then, with 